\title{
TESTING OF A CHEMILUMINESCENCE ENZYME IMMUNOASSAY FOR SELECTIVE DETECTION OF E. COLI O157 FROM GROUND BEEF SAMPLES
}

\author{
Hajnalka DOMJÁN KovÁCS ${ }^{1 *}$ and Klára RÁSKY ${ }^{2}$ \\ ${ }^{1}$ National Food Investigation Institute, H-1465 Budapest 94, P.O. Box 1740, Hungary; \\ ${ }^{2}$ Diagnosticum Ltd, H-1047 Budapest, Attila u. 126, Hungary
}

(Received September 11, 2001; accepted September 28, 2001)

\begin{abstract}
The aim of this study was to evaluate a Chemiluminescence Enzyme Immunoassay (CLIA) developed for the detection of E. coli O157:H7, using different $E$. coli $\mathrm{O} 157$ serotypes. The sensitivity and specificity of the kit were determined from the tenfold dilutions of the 24-hour broth cultures of the test strains. According to the results obtained in this trial, the sensitivity of the kit is $10^{3}-$ $10^{4}$ cells $\mathrm{ml}^{-1}$, and it is specific for E. coli O157. Twenty-five g ground raw beef samples were prepared and inoculated with $E$. coli $\mathrm{O} 157: \mathrm{H} 7$ at different $\mathrm{CFU} \mathrm{g}^{-1}$. The samples were incubated in $225 \mathrm{ml}$ of modified $E$. coli broth with novobiocin $(\mathrm{mEC}+\mathrm{n})$ at $42{ }^{\circ} \mathrm{C}$ for $4 \mathrm{~h}$ and the immunoassays were performed following the instructions of the manufacturer. According to the results obtained by the CLIA test $10^{1}-10^{2}$ E. coli $\mathrm{O} 157 \mathrm{~g}^{-1}$ can be detected from the sample. So this kit seems to be suitable for screening the samples before selective cultivation of E. coli O157:H7.
\end{abstract}

Key words: E. coli O157:H7, Chemiluminescence Enzyme Immunoassay, screening, ground beef

Verocytotoxin-producing E. coli (VTEC) are now recognised as a major cause of haemorrhagic colitis and haemolytic-uraemic syndrome. Although a wide variety of VTEC serogroups have been implicated in human disease, E. coli O157:H7 are the most prevalent strains. E. coli $\mathrm{O} 157: \mathrm{H} 7$ is considered a newly emerged pathogen. The severity of the resulting disease, together with the potential reservoir of E. coli O157:H7 in cattle, makes it a serious risk to human health. Many cases and outbreaks of O157 VTEC infection have been linked to the consumption of contaminated beef products (Armstrong et al., 1996; Uyttendalee and Debevere, 1997). Since these pathogenic bacteria may be present in food and environmental samples in only small numbers (and $<100$ O157:H7 bacteria may be infective), sensitive methods are needed for their detection (Okrend et al., 1990).

\footnotetext{
*Corresponding author: Dr. Kovácsné Dr. Domján Hajnalka, H-1118 Budapest, Bakator
} u. 3, Hungary; E-mail: oai@oai.hu; Fax: +36 (1) 216-1574 
Several methods have been developed for the detection and isolation of $E$. coli $\mathrm{O} 157$ from food and other samples. Selective enrichment and plating media (Benneth et al., 1995; Heuvelink et al., 1997) as well as commercial test kits (Grif et al., 1997; Ness and Krona, 1997; Heckötter et al., 1997) were compared to find eventually a sensitive, practical and rapid method for detecting $\mathrm{O} 157$ VTEC from minced beef.

In this study we performed model experiments on a newly developed Chemiluminescence Enzyme Immunoassay (CLIA) Kit, which is designed for the qualitative detection of $E$. coli $\mathrm{O} 157$. The aim of the study was to evaluate the CLIA test in experiments with different $E$. coli $\mathrm{O} 157$ strains to determine its sensitivity, reproducibility and specificity with special regard to the detection of E. coli $\mathrm{O} 157$ in ground beef.

\section{Materials and methods}

Strains

The following Escherichia coli strains were used: strain 2409 O157:H7 SLT I-II (human); strain 7785 O157:H7 (human); strain 13888 O157:H7 ATCC; strain 123 O43:K-:H28 (porcine); strain 2041 O157; K88ac STL+LT+ (porcine); strain 2134 O157; F18ac STC+STb+ (porcine); strain 198 O157 H (non H7 from cattle).

\section{Culture media}

Beef extract broth ( $\mathrm{pH} 7.4$ ) saline with $0.1 \%$ pepton, VRB lactose agar (Oxoid $\mathrm{CM}$ b7), modified $E$. coli broth with novobiocin $(\mathrm{mEc}+\mathrm{n})$ were used.

\section{Chemiluminescence Enzyme Immunoassay (CLIA)}

CLIA Kit for E. coli O157 (GEM Biomedical Inc. USA) was used for the detection of E. coli O157. The test was carried out following the instructions of the manufacturer. Briefly, purified antibodies to E. coli O157 antigen - adsorbed on the solid phase of the plastic test tube - reacted with the E. coli $\mathrm{O} 157$ bacteria present in the previously enriched samples. The antigen/antibody immune complex was detected with peroxidase-labelled second antibodies after 10 min reaction with luminogenic substrate.

A chemiluminescence detection system was used for the measurement of the immune complexes formed in the previous immune reaction. The luminometer 'Leader 50' was used for reading the Relative Light Unit (RLU).

Negative and positive controls were also supplied by the manufacturer. Positive assay control provides verification of the functionality of the assay and negative assay control was used for the calculation of the test cut-off value ( 5 
times of the mean RLU value of the negative control). Samples with RLU less than the cut-off are considered to be negative and samples with RLU values greater or equal to the cut-off are considered to be positive for the presence of $E$. coli O157. Each sample was tested in duplicate tests.

\section{Experiments on test strains}

To test the sensitivity of the kit, 24-hour broth cultures (nutrient broth) of E. coli of different serotypes were used. Tenfold dilutions in saline were made and the $10^{-2}-10^{-7}$ dilutions were applied.

The number of $E$. coli $\mathrm{ml}^{-1}$ in the 24-hour broth culture was controlled by determining the titre value and by colony count technique on agar plates. One $\mathrm{ml}$ of each of the dilutions $10^{-1}-10^{-10}$ was inoculated into $10 \mathrm{ml}$ nutrient broth, and in parallel $0.1 \mathrm{ml}$ was plated onto the VRB lactose agar from the $10^{-5}-10^{-8}$ dilutions. The broth cultures and the agar plates were incubated at $37^{\circ} \mathrm{C}$ for $24 \mathrm{~h}$.

\section{Preparation of inoculated raw ground meat samples}

Pilot experiment. A culture of E. coli $\mathrm{O} 157: \mathrm{H} 7$ was grown overnight in nutrient broth. Decimal dilutions to $10^{-10}$ were made in saline. Retail ground beef balls, free from E. coli $\mathrm{O} 157,10 \mathrm{~g}$ each, were placed into individual plastic bags and stabbed with a sterile pipette to produce holes heading to the centre of the balls. Each sample was inoculated in the hole with $1.0 \mathrm{ml}$ of dilutions $10^{0}, 10^{-1}$, $10^{-2}, 10^{-3}$ of the cultures, and $90 \mathrm{ml}$ saline was added. The samples were homogenised for $2 \mathrm{~min}$ in Colworth Stomacher Blender and directly, without enrichment, $100 \mu 1$ of each suspended sample was tested with the kit. The method used for controlling the inoculation level of the samples was the same as indicated in the section Experiments on test strains.

Main experiments. Different strains of E. coli $\mathrm{O} 157$ were incubated overnight in nutrient broth and decimal dilutions to $10^{-10}$ were made in saline. Retail ground beef balls, $25 \mathrm{~g}$ each, were placed in plastic bags and were inoculated with $2.5 \mathrm{ml}$ of the dilutions $\left(10^{-3}-10^{-8}\right) .225 \mathrm{ml} \mathrm{EC}$ broth was added to the inoculated samples and stomached. The homogenised samples were incubated at $42{ }^{\circ} \mathrm{C}$ for $4 \mathrm{~h}$ before CLIA analysis.

On one occasion the analysis was performed three times: immediately, $4 \mathrm{~h}$ and $24 \mathrm{~h}$ after the inoculation. Plate counts done on the tenfold dilutions of the inoculum showed that samples inoculated with $2.5 \mathrm{ml}$ of the dilutions routinely received $10^{6}-<10^{1}$ organisms $\mathrm{g}^{-1}$.

Statistical analysis for determination of between-assay variations was done based on seven determinations/sample using standard statistical methods for means, standard deviations and coefficients of variation. 


\section{Results and discussion}

The results of experiments performed on the test strains of different serotypes to determine the sensitivity and specificity of the kit are demonstrated in Table 1. As the table shows, the kit gives specific result with E. coli $\mathrm{O} 157$ independently of other characteristic features of the serotypes ( $\mathrm{H} 7$, other than $\mathrm{H} 7)$, and the sensitivity of the kit is between $10^{3}-10^{4}$ organisms $^{-1} \mathrm{ml}$.

Table 1

\begin{tabular}{|c|c|c|c|c|c|}
\hline \multicolumn{6}{|c|}{ Experiments on strains } \\
\hline \multirow{2}{*}{ Strains } & \multirow{2}{*}{$\mathrm{CFU} \mathrm{ml^{-1 }}$} & \multicolumn{4}{|c|}{ Results of CLIA test no. } \\
\hline & & I & II & III & IV \\
\hline \multicolumn{6}{|l|}{ E. coli } \\
\hline 2409 & $10^{4}$ & - & + & + & - \\
\hline $\mathrm{O} 157: \mathrm{H} 7$ & $10^{3}$ & + & - & - & + \\
\hline $\begin{array}{l}\text { E. coli } \\
\text { 2041 } \\
\text { O157:K88 }\end{array}$ & $10^{3}$ & + & & & \\
\hline $\begin{array}{l}\text { E. coli } \\
2134 \\
\text { O157:F18 }\end{array}$ & $10^{3}$ & + & & & \\
\hline $\begin{array}{l}\text { E. coli } \\
7785 \\
\text { O157:H7 }\end{array}$ & $10^{3}$ & + & & & \\
\hline $\begin{array}{l}\text { E. coli } \\
138 \\
\text { O157:H7 }\end{array}$ & $10^{4}$ & + & & & \\
\hline $\begin{array}{l}\text { E. coli } \\
198 \\
\text { O157:H? }\end{array}$ & $10^{4}$ & + & & & \\
\hline $\begin{array}{l}\text { E. coli } \\
123\end{array}$ & $10^{6}$ & - & & & \\
\hline
\end{tabular}

\section{Experiments with inoculated meat samples}

The results of the pilot experiment with $10 \mathrm{~g}$ inoculated ground meat samples are shown in Table 2. These results chime in with those of the experiment on the test strains. The kit is able to detect $10^{4} \mathrm{CFU} \mathrm{g}^{-1} \mathrm{E}$. coli by direct determination without enrichment procedure. 
Table 2

Pilot experiment with 10 -g meat sample

\begin{tabular}{lcc}
\hline \multicolumn{1}{c}{ Strain } & $\begin{array}{c}\text { Meat } \\
\mathrm{CFU} \mathrm{g}^{-1}\end{array}$ & $\begin{array}{c}\text { Results of CLIA test } \\
\text { without enrichment }\end{array}$ \\
\hline E. coli & $10^{6}$ & + \\
2409 & $10^{5}$ & + \\
O157:H7 & $10^{4}$ & + \\
& $10^{3}$ & - \\
\hline
\end{tabular}

According to the descriptions of the kit, the assay is based on the ability of the kit to detect E. coli $\mathrm{O} 157$ in previously enriched samples. The $25 \mathrm{-g}$ ground beef samples with different inocula were tested several times. In the first step the samples were examined directly after inoculation and after 4-h enrichment as well as after an overnight enrichment. The results are shown in Table 3. It can be seen that the levels of detectability reached the $10^{1}$ and $<10^{1} / 9^{-1}$ thresholds after the enrichment procedures.

Table 3

Main experiments with 25-g meat sample without enrichment, with 4-h enrichment and with overnight enrichment

\begin{tabular}{|c|c|c|c|c|c|c|}
\hline \multirow{3}{*}{ Strain } & \multirow{3}{*}{$\begin{array}{c}\text { Meat } \\
\text { CFU g }^{-1}\end{array}$} & \multicolumn{5}{|c|}{ Results of CLIA test } \\
\hline & & \multicolumn{2}{|c|}{ Directly } & \multicolumn{2}{|c|}{ 4-h enrichment } & \multirow{2}{*}{$\begin{array}{c}\begin{array}{c}\text { Overnight } \\
\text { enrichment }\end{array} \\
\text { I }\end{array}$} \\
\hline & & I & II & I & II & \\
\hline \multicolumn{7}{|l|}{ E. coli } \\
\hline 2409 & $10^{5}$ & + & + & + & + & + \\
\hline \multirow[t]{5}{*}{ O157: H7 } & $10^{4}$ & + & - & + & + & + \\
\hline & $10^{3}$ & - & - & + & + & + \\
\hline & $10^{2}$ & - & - & + & + & + \\
\hline & $10^{1}$ & - & - & + & + & + \\
\hline & $<10^{1}$ & - & - & - & - & + \\
\hline
\end{tabular}

The study was continued with experiments on 25 -g inoculated meat samples with 4-h enrichment in four repeats. The results are presented in Table 4. It can be seen that in case of sample analysis after the 4-h enrichment the sensitivity of the kit may increase to $10^{1}-10^{2}$ E. coli $\mathrm{O} 157$ in meat $\mathrm{g}^{-1}$. The controls and the samples in each run of the test were used in duplicates, so the between-assay variation of the assays was determined and is shown in Table 5. 
Table 4

Experiments with 25-g meat samples inoculated with E. coli $\mathrm{O} 157: \mathrm{H} 7$

\begin{tabular}{|c|c|c|c|c|c|}
\hline \multirow{2}{*}{ Strains } & \multirow{2}{*}{$\begin{array}{c}\text { Meat } \\
\text { CFU g g }^{-1}\end{array}$} & \multicolumn{4}{|c|}{ Results of CLIA tests with 4-h enrichment no. } \\
\hline & & I & II & III & IV \\
\hline \multicolumn{6}{|l|}{ E. coli } \\
\hline 2409 & $10^{3}$ & + & + & + & + \\
\hline \multirow[t]{2}{*}{$\mathrm{O} 157: \mathrm{H} 7$} & $10^{2}$ & - & + & - & + \\
\hline & $10^{1}$ & - & + & - & + \\
\hline \multicolumn{6}{|l|}{ E. coli } \\
\hline 7785 & $10^{3}$ & + & + & + & + \\
\hline \multirow[t]{2}{*}{ 0157:H7 } & $10^{2}$ & + & + & - & + \\
\hline & $10^{1}$ & - & + & - & + \\
\hline \multicolumn{6}{|l|}{ E. coli } \\
\hline 13888 ATCC & $10^{3}$ & + & + & + & + \\
\hline \multirow[t]{2}{*}{ 0157:H7 } & $10^{2}$ & + & + & - & + \\
\hline & $10^{1}$ & + & + & - & + \\
\hline
\end{tabular}

Table 5

Between-assay variation of the assay

\begin{tabular}{lcl}
\hline \multicolumn{1}{c}{ Determination, $\mathrm{n}=7$} & $\mathrm{RLU} \pm \mathrm{SD}$ & $\mathrm{CV} \%$ \\
\hline Background & $834 \pm 147$ & 17.6 \\
Negative control & $817 \pm 166$ & 20 \\
Positive control & $808,605 \pm 15,146$ & 18.8 \\
\hline
\end{tabular}

From the results of our study on this CLIA test it can be concluded that, following a previous 4-h enrichment procedure of the food sample, the kit is able to detect $10^{1}-10^{2}$ E. coli $\mathrm{O} 157 \mathrm{~g}^{-1}$ in an about 7-h working period.

Still no simple and sensitive procedures are available for the direct cultivation of $E$. coli $\mathrm{O} 157: \mathrm{H} 7$. The application of this CLIA kit as a screening test for the specific detection of $E$. coli $\mathrm{O} 157: \mathrm{H} 7$ reduces the work needed for the conventional detection of $E$. coli $\mathrm{O} 157: \mathrm{H} 7$. The CLIA kit can be used for testing samples contaminated with even less than $10^{2}$ E. coli $\mathrm{O} 157 \mathrm{~g}^{-1}$. Therefore it can be recommended for quick mass screening of possibly contaminated raw meat samples (and possibly of other food samples as well). 


\section{Acknowledgements}

The authors wish to thank Béla Nagy (Veterinary Medical Research Institute, Hungarian Academy of Sciences), and Ferenc Pétery (Diagnosticum Ltd.) for initiating the study and providing the strains. The technical assistance of Krisztina Fias, Andrea Szalavári and Irén Csala is also gratefully acknowledged.

\section{References}

Armstrong, G. L., Hollingsworth, J. and Morris, Jr. G. J. (1996): Emerging foodborne pathogens: Escherichia coli $\mathrm{O} 157: \mathrm{H} 7$ as a model of entry of a new pathogen into food supply of the developed world. Epid. Rev. 18, 29-50.

Benneth, A. R., MacPhee, S. and Belts, R. P. (1995): Evaluation of methods for isolation and detection of Escherichia coli $\mathrm{O} 157$ in minced beef. Letters Appl. Microbiol. 20, 375-379.

Grif, K., Dierich, M. P. and Allerberger, F. (1997): Dynabeads ${ }^{\mathrm{TM}}$ plus 3M Petrifilm HEC ${ }^{\mathrm{TM}}$ : an improved screening method for detection of E. coli 0157 from minced beef. Int. Symp. European Study Group on Enterohemorrhagic Escherichia coli 2nd Meeting, 12-13 April 1997, Innsbruck, Austria, Monograph 84, 47.

Heckötter, S., Schuy, C. and Bülte, M. (1997): Detection of Escherichia coli O157:H7 in minced meat by immunomagnetic separation (IMS) in model experiment. Proceedings of the World Congress on Food Hygiene (WAVFH), 24-29 August, The Hague, The Netherlands, p. 120.

Heuvelink, A. E., Verhagen, E., Zwartkruis, A. and Boer, E. (1997): Evaluation of media and test kits for detection and isolation of Escherichia coli 0157 from minced beef. 17th Meeting of ISO/TC 34 SC9. Food and Agricultural Products - Microbiology, 30 June-2 July 1997, Turin, Italy. Circular letter.

Ness, V. and Krona, R. (1997): Detection of E. coli O157 by immunomagnetic separation combined with chromogenic plating media. European Study Group on Enterohemorrhagic Escherichia coli 2nd Meeting, 12-13 April 1997, Innsbruck, Austria, Monograph 84, 47-53.

Okrend, A. J. G., Rose, B. E. and Matner, R. (1990): An improved screening method for the detection and isolation of Escherichia coli $\mathrm{O} 157: \mathrm{H} 7$ from meat, incorporating the M Petrifilm ${ }^{\mathrm{TM}}$ Test Kit - HEC-for hemorrhagic Escherichia coli O157:H7. J. Food Prot. 53, 936-940.

Uyttendalee, M. R. and Debevere, J. M. (1997): Characteristics, prevalence and control of E. coli O157:H7 in foods. Proceedings of the World Congress on Food Hygiene (WAVFH), 24-29 August, The Hague, The Netherlands, p. 109. 